\title{
O IMPACTO DA PANDEMIA DA COVID-19 NA (IN) SEGURANÇA ALIMENTAR DA POPULAÇÃO BRASILEIRA SOB A ÓTICA INTERCULTURAL E INTERDISCIPLINAR
}

\author{
Regina Aparecida Messias Guilherme ${ }^{1}$ \\ Emmanuel Pereira de Carvalho ${ }^{2}$ \\ Katia Cilene Tabai ${ }^{3}$
}

\begin{abstract}
Resumo: Este artigo figura no âmbito da intersetorialidade para alcançar a segurança alimentar, considerando o impacto da pandemia da COVID-19 e as suas consequências. Neste sentido, com a perspectiva da interdisciplinaridade traz uma contribuição para sociedade, dentro de uma reflexão advinda da interculturalidade, mobilizada pelo diálogo das culturas, a fim de promover a soberania alimentar dentro desse cenário de incertezas, que requer a vigência de políticas públicas intersetoriais de alimentação, saúde, educação, habitação, entre outras, que sejam eficazes. E ainda, destacou-se estudos que relatam a relação do elevado número de pessoas acometidas pela pandemia com a má nutrição, que vai desde a fome, até muitas vezes, ao sobrepeso e a obesidade, bem como a questão da alimentação do brasileiro e, com isso nos remete a necessidade de promover sistemas alimentares sustentáveis. Sugere-se entre outros aspectos, que dentre as prioridades governamentais, estejam a proteção de populações mais vulneráveis do ponto de vista econômico e social, para erradicar a fome no Brasil.

Palavras-chave: sistemas alimentares sustentáveis, segurança alimentar, interdisciplinaridade, políticas públicas intersetorias, pandemia.
\end{abstract}

\section{THE IMPACT OF THE COVID-19 PANDEMIC ON THE (IN) FOOD SECURITY OF THE BRAZILIAN POPULATION FROM THE INTERCULTURAL AND INTERDISCIPLINARY PERSPECTIVE}

\begin{abstract}
This article is part of the intersectoral framework to achieve food security, considering the impact of the COVID-19 pandemic and its consequences. In this sense, with the perspective of interdisciplinarity, it makes a contribution to society, within a reflection arising from interculturality, mobilized by the dialogue of cultures, in order to promote food sovereignty within this scenario of uncertainties, which requires the existence of intersectoral public policies food, health, education, housing, among others, that are effective. And yet, studies that report the relationship between the high number of people affected by the pandemic and malnutrition stood out, ranging from hunger, to often, overweight and obesity, as well as the question of the Brazilian's diet and, with that, it reminds us of the need to promote sustainable food systems. Among other aspects, it is suggested that among that governmental priorities are the protection of the most vulnerable populations from the economic and social point of view, to eradicate hunger in Brazil.
\end{abstract}

Keywords: sustainable food systems, food security, interdisciplinarity, intersectoral public policies, pandemic.

\footnotetext{
1 Professora Assistente. Departamento de Educação. Universidade Estadual de Ponta Grossa - UEPG. Mestre em Educação. Grupo de pesquisa no CNPq: Segurança Alimentar e Nutricional (SAN). E-mail: reginaamguilherme@hotmail.com

${ }^{2}$ Mestrando pelo Programa em Práticas em Desenvolvimento Sustentável - PPGDS da Universidade Federal Rural do Rio de Janeiro - UFRRJ. Arquiteto e Urbanista. Grupo de pesquisa no CNPq: Segurança Alimentar e Nutricional (SAN). E-mail: epcarquitetura@gmail.com Lattes: http://lattes.cnpq.br/2887087285663903

${ }^{3}$ Professora Titular. Universidade Federal Rural do Rio de Janeiro - UFRRJ. Docente permanente nos Programas de Pós-Graduação em Práticas em Desenvolvimento Sustentável - PPGPDS e em Agricultura Ogânica - PPGAO. Líder do Grupo de pesquisa no CNPq: Segurança Alimentar e Nutricional (SAN). E-mail: ktabai@ufrrj.br
} 


\section{Introdução}

A Organização das Nações Unidas para Alimentação e Agricultura (FAO), revela que o número de pessoas em situação de insegurança alimentar no mundo alcançou um bilhão de indivíduos. $\mathrm{O}$ fator mais determinante da insegurança alimentar é a baixa renda domiciliar per capita, que explicita a importância de programas governamentais para populações carentes como, por exemplo, o programa de transferência de renda vigente no Brasil, o 'Bolsa Família'. Além disso, sabe-se que a alta dos preços dos alimentos acaba sendo uma ameaça à sobrevivência de famílias consideradas realmente pobres (TABAI, 2018).

A soberania e segurança alimentar ${ }^{4}$ são extremamente importantes ainda mais nos dias atuais, onde, sabe-se que, milhões de trabalhadores estão desempregados no Brasil (IBGE, 2020a). O Instituto Brasileiro de Geografia e Estatística - IBGE (2020a), por meio da Pesquisa Nacional por Amostra de Domicílio - PNAD, na pandemia da Covid-19, apontou dados extremamente preocupantes e que devem ser levados em consideração, especificamente no que diz respeito a renda, por ter relação direta com a compra de alimentos e, consequentemente, com a segurança alimentar $^{5}$, a taxa de desemprego no país, por exemplo, que vem crescendo representa o agravo ainda maior com a falta de renda para grande parte dos brasileiros e com isso a situação de insegurança alimentar tende a ser ainda maior.

Acredita-se que, atualmente o problema torna-se ainda mais grave devido a pandemia da Covid-19, pois pelo que temos observado essa epidemia no Brasil tem atingido de forma desigual na sociedade. Infelizmente o novo coronavírus (SARS-CoV-2) tem impactado os territórios urbanos brasileiros de uma maneira geral. Alguns dados revelam que o número de casos e de mortes por COVID-19 tende a ser maior nas áreas periféricas (FAPESP, 2020). Além disso, o gasto com a alimentação e a habitação são as maiores despesas das famílias, em especial as de baixa renda. A última Pesquisa de Orçamentos Familiares, a POF de 2017-2018, revelou que as

\footnotetext{
${ }^{4}$ Entende-se por soberania alimentar dos povos, a produção dos alimentos que respeita a cultura e hábitos de consumo da população, sendo crucial para garantir a Segurança Alimentar e Nutricional - SAN, pois garante que os indivíduos tenham autonomia para produzir e definir para quem irão produzir. O conceito de soberania alimentar, sob a ótica da segurança alimentar, frisa que para o povo ser soberano, essa soberania refere-se a condição de alimentar o seu povo, precisamos ter plena condição de se alimentar, ter renda suficiente para adquirir os alimentos (BRASIL, 2006; TABAI, 2018).

${ }^{5}$ De acordo com o artigo $4^{\circ}$. da Lei Orgânica de Segurança Alimentar e Nutricional - LOSAN, a segurança alimentar pode ser definida como a garantia da qualidade biológica, sanitária, nutricional e tecnológica dos alimentos, bem como seu aproveitamento, estimulando práticas alimentares e estilos de vida saudáveis que respeitem a diversidade étnica e racial e cultural da população (BRASIL, 2006). A LOSAN foi um marco para a segurança alimentar, no entanto, lamentavelmente o Conselho Nacional de Segurança Alimentar - CONSEA, na gestão atual do governo federal, está suspenso, o que representa, no mínimo, uma descontinuidade nas políticas públicas na área de SAN.
} 
famílias com renda de até $\mathrm{R} \$ 1,9$ mil, destinam a maior parte, a saber, 61,2\% de seus gastos à alimentação e a habitação (IBGE, 2019).

A pandemia da COVID-19 tem afetado a segurança alimentar e nutricional no país. Praticamente a metade da população brasileira (49\%) relatou mudanças nos hábitos alimentares (UNICEF, 2020). Silva (2020) destacou o elevado número de pessoas acometidas pela pandemia da COVID-19 com a má nutrição, que vai desde a fome até, muitas vezes, o sobrepeso e a obesidade, bem como o maior alcance aos mais pobres, que vivem em condições de maior vulnerabilidade, por isso estão sendo mais contaminadas devido ao maior risco de contágio.

Para alguns autores a alimentação pode ser vista como um meio de comunicação, uma ferramenta de identidade e a maneira como as pessoas lidam com as diferentes culturas. Sendo que as noções de identidade estão fortemente ligadas ao senso de identidade de lugar e de pertencimento. Morais (2011) enfoca que a comida desempenha um papel importante na sociedade, vindo a se constituir em operações universais, também marcando estilos e delimitando territorialidades. Entendendo o quanto esse assunto é importante e os poucos estudos sobre os diferentes impactos de políticas públicas relacionados à alimentação e à nutrição, pretendeu-se apresentar nesta abordagem de que forma as pessoas precisam de ações em prol da soberania e segurança alimentar sob a ótica da identidade alimentar e cultura alimentar na perspectiva interdisciplinar, intersetorial e intercultural. Neste sentido, cabem algumas aproximações com a filosofia intercultural para adentrar aos caminhos do diálogo das culturas, em especial nesta época de enfrentamento à pandemia da COVID-19, em que, ressurgem as necessidades para a incidência de políticas públicas intersetoriais.

\section{Alimentação como direito humano}

A alimentação adequada e saudável é um direito humano básico que envolve a garantia ao acesso permanente e regular, de forma socialmente justa, a uma prática alimentar adequada aos aspectos biológicos e sociais do indivíduo e que deve estar em acordo com as necessidades alimentares especiais; ser referenciada pela cultura alimentar e pelas dimensões de gênero, raça e etnia; acessível do ponto de vista físico e financeiro; harmônica em quantidade e qualidade, atendendo aos princípios da variedade, equilíbrio, moderação e prazer; e baseada em práticas produtivas adequadas e sustentáveis, viabilizando assim o necessário diálogo das culturas a partir da interculturalidade (BRASIL, 2014 citado por TABAI, 2017).

A alimentação como direito humano não estava contemplada na Constituição Brasileira de 1988, foi incluída no artigo $6^{\circ}$. da Constituição Federal como direito social, na emenda 
constitucional $n^{\circ}$. 64 apenas em 2010, no entanto é importante frisar que embora esteja oficialmente na constituição, sabemos que ainda não está sendo garantida para todos, infelizmente (TABAI, 2018).

Segurança Alimentar e Nutricional é essencialmente interdisciplinar (TABAI, 2017), para tanto as reflexões em tela se destinam para propiciar uma travessia neste cenário de pandemia, no qual a condição humana abstrata, instaurando uma dialética e uma ciência cidadã face às políticas necessárias para serem priorizados os sistemas alimentares sustentáveis. Sabe-se que as diferentes políticas se relacionam com as políticas de saneamento ambiental, por exemplo, sendo considerada importante para a relação dessa política com a habitação, uma vez que as condições de saúde de um indivíduo estão estritamente ligadas às suas condições de moradia, que por outro lado estão relacionadas às demais políticas.

A Pesquisa de Orçamentos Familiares (POF) 2017-2018 realizada pelo IBGE (2020b), divulgou que aproximadamente 10,3 milhões de pessoas encontram-se em situação de insegurança alimentar grave, isto significa que existe privação grave de alimentos, ou seja, são pessoas passando fome. Maluf (2020a) relata que essa insegurança alimentar grave já chegou a atingir quase $5 \%$ das famílias brasileiras e que estes percentuais se aproximam ao patamar do percentual que recoloca o país, de novo, ao vergonhoso Mapa da Fome que tanto lutamos para sair.

É importante frisar que a segurança alimentar e nutricional não se restringe ao combate à fome e à pobreza e, embora a fome e a desnutrição sejam as manifestações mais graves, outras variáveis podem impedir a SAN, a saber: carências de micronutrientes, excesso de peso e transtornos alimentares, que implicam em muitos riscos à saúde e impacto nas famílias, no mercado de trabalho, no sistema de saúde e na sociedade em geral. Dados sobre a alimentação da população brasileira divulgados nos últimos anos são alarmantes, por exemplo, na última Pesquisa de Orçamentos Familiares (POF), constatou-se evidência do desequilíbrio alimentar. O declínio do consumo de vegetais frescos e o aumento da ingestão de açúcar, foi promovido pelo acréscimo da disponibilidade domiciliar de bebidas processadas (sucos, refrescos e refrigerantes) principalmente entre adolescentes e jovens (IBGE, 2020b).

A concepção de Segurança Alimentar e Nutricional se baseia na garantia da universalidade e equidade do acesso à alimentação, intersetorialidade das políticas, descentralização e articulação das ações, respeito à diversidade e à especificidade socioterritorial, participação social e transparência na gestão das políticas. Entende-se por intersetorialidade, a possibilidade de síntese de políticas e, esta por sua vez, está no reconhecimento dos limites de poder e de atuação dos setores, pessoas e instituições. A ação intersetorial não elimina a importância da existência de espaços específicos de gestão de políticas setoriais e a adoção da intersetorialidade, tende a 
favorecer políticas e ações que sejam influenciadas pela dinâmica de outros setores. A questão fundamental da intersetorialidade é a ruptura das barreiras de comunicação, que impedem o diálogo entre diferentes setores. A intersetorialidade surge como uma estratégia alternativa de gestão social, embora a implementação exiga a superação de grandes desafios (NASCIMENTO, 2010).

O Brasil vem passando por diversas mudanças políticas, econômicas, sociais e culturais que resultaram em transformações no modo de vida da população. Entre as principais mudanças, destaca-se a rápida transição nutricional, como a diminuição da desnutrição e o aumento da obesidade na população brasileira. Nos últimos anos, o Brasil vem enfrentando aumento expressivo do sobrepeso e da obesidade em todas as faixas etárias, e as doenças crônicas não transmissíveis são a principal causa de morte entre adultos. E ainda, os problemas de sobrepeso e obesidade, muitas vezes, coincidem com os problemas de ingestão inadequada de alimentos e micronutrientes; estes problemas não são limitados apenas para os países de baixa renda. No entanto, a desnutrição crônica ainda prevalece em grupos vulneráveis da população, como em crianças e mulheres que vivem em áreas mais vulneráveis. Para reverter esse quadro de precariedade, é necessário a ampliação de ações intersetoriais sobre os diversos determinantes da saúde e nutrição (BRASIL, 2014 citado por TABAI, 2018).

O Ministério da Saúde acredita que o setor saúde tem importante papel para promover alimentação adequada e saudável, compromisso expresso na Política Nacional de Alimentação e Nutrição e na Política Nacional de Promoção da Saúde. E que a promoção da alimentação adequada e saudável no Sistema Único de Saúde (SUS), deve fundamentar-se nas dimensões de incentivo, apoio e proteção da saúde e deve combinar iniciativas focadas em políticas públicas saudáveis, na criação de ambientes saudáveis, no desenvolvimento de habilidades pessoais e na reorientação dos serviços de saúde na perspectiva da promoção da saúde. O Guia Alimentar para a População Brasileira aborda os princípios e as recomendações de uma alimentação adequada e saudável para a população brasileira, configurando-se como instrumento de apoio às ações de educação alimentar e nutricional no SUS e, também, em outros setores. Considerando os fatores determinantes das práticas alimentares e, a complexidade e os desafios que envolvem a conformação dos sistemas alimentares atuais, o guia alimentar reforça o compromisso do Ministério da Saúde em contribuir para o desenvolvimento de estratégias para a promoção e a realização do Direito Humano à Alimentação Adequada - DHAA (BRASIL, 2014).

A Organização das Nações Unidas (ONU, 2015), baseando-se nos indicadores econômicos, sociais e ambientais dos últimos anos, propôs que os seus países membros assinassem a Agenda 2030, um plano global composto por 17 objetivos (ODSs ) e 169 metas para que esses países 
alcancem o desenvolvimento sustentável em todos os âmbitos até 2030. É importante frisar que, cada objetivo e suas respectivas metas abordam aspectos diferentes, mas que convergem pelo fato de serem essenciais para a viabilidade de uma sociedade sustentável; baseada em práticas produtivas adequadas e sustentáveis, oportunizando assim o necessário diálogo inclusive das culturas a partir da interculturalidade. Para os fins dessa abordagem, destaca-se o objetivo número 2, a saber, o fome zero e agricultura sustentável, no entanto é importante lembrar que tanto o objetivo número 1, que diz respeito a erradicação da pobreza, bem como o ODS 10, a redução das desigualdades, são extremamente importantes para alcançarmos a segurança alimentar, bem como os demais ODS (ONU, 2015). Todos os países membros da ONU assinaram essa agenda com o compromisso de alcançar as metas dos 17 objetivos, conforme ilustrado na imagem a seguir:

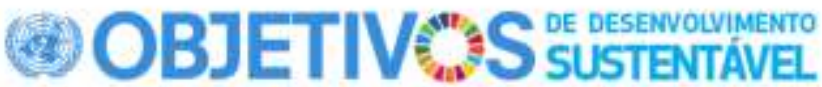

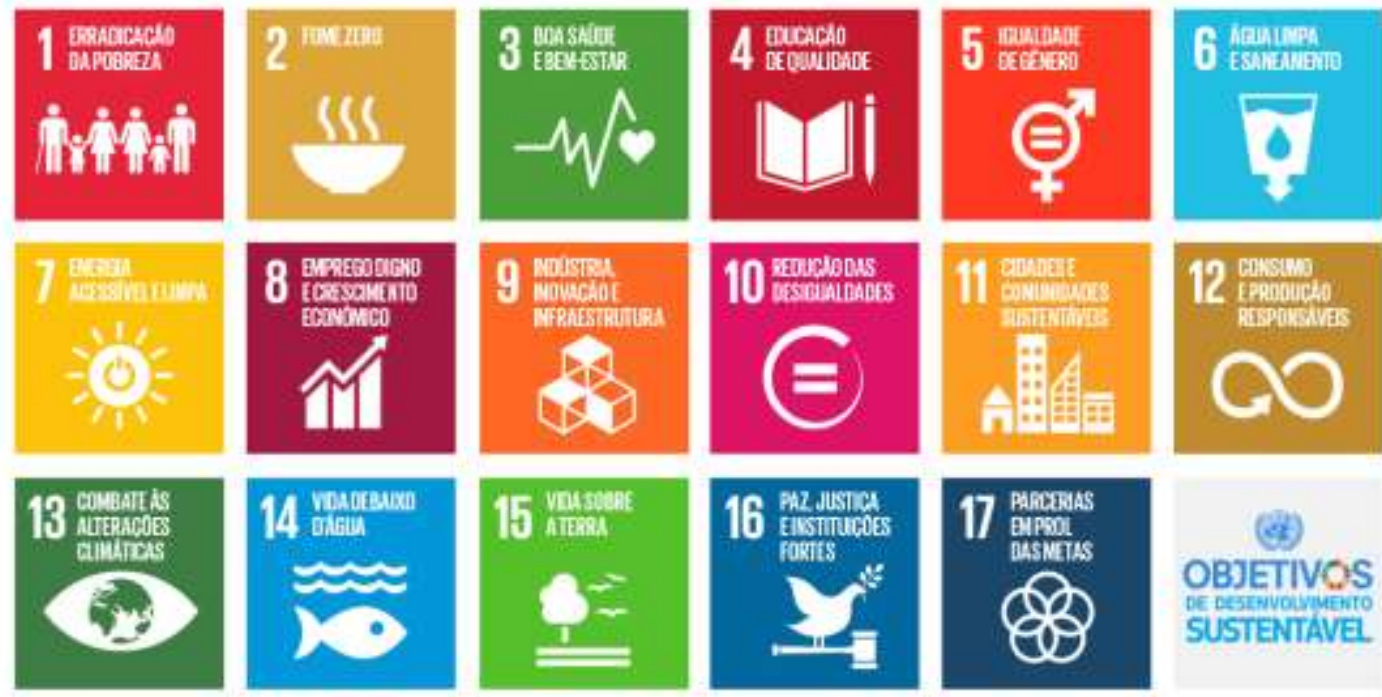

Fonte: ONU (2015).

É importante destacar que a alimentação adequada e saudável é um direito humano fundamental que abrange a garantia do acesso permanente e regular, de forma socialmente justa, a uma prática alimentar adequada aos aspectos biológicos e sociais do indivíduo, que deve estar em conformidade com as necessidades alimentares particulares; ser referenciado pela cultura alimentar e pelas dimensões de gênero, raça e etnia; acessível do ponto de vista físico e financeiro; harmonioso em quantidade e qualidade, respondendo aos princípios de variedade, equilíbrio, moderação e prazer; e com base em práticas produtivas adequadas e sustentáveis, permitindo o necessário diálogo entre culturas pautadas na interculturalidade (BRASIL, 2014). 
Medidas como a Lei 14.016 de 23 de junho de 2020, publicada durante a pandemia, por exemplo, que dispõe sobre o desperdício de alimentos e a doação de excedentes de alimentos para o consumo humano, possam ser mecanismos que sirvam como uma das ações estratégicas de segurança alimentar, em especial durante a pandemia da COVID-19, onde tantas pessoas poderão ser beneficiadas com a doação de alimentos que outrora seriam jogados fora, por precaução jurídica (BRASIL, 2020a).

Com o decorrer do tempo, o avanço da pandemia do coronavírus e, consequentemente, a manutenção da quarentena aqui no Brasil também, propiciou-se algumas alterações na legislação e foram feitas inclusive em relação a Lei n 11.947 , no que diz respeito ao Programa Nacional de Alimentação Escolar, em especial a distribuição da alimentação escolar ${ }^{6}$ (BRASIL, 2020b). No entanto, o que pudemos observar infelizmente, em muitos lugares, foi um despreparo dos gestores públicos nos repasses dos valores destinados às famílias dos escolares, seja por meio de kits insuficientes, número menor de cestas básicas do que a demanda necessária, ou cartões alimentação que não foram planejados adequadamente, em suma, houve atrasos, falta de encaminhamentos, o que gerou grandes expectativas, para as famílias mais carentes, resultando quase sempre em uma espera frustrada ${ }^{7}$, essa falta de agilidade no recebimento desse direito a essa alimentação dos escolares gerou no mínimo maior insegurança alimentar para as crianças e suas famílias que, muitas vezes, estavam em situação grave pela ausência de comida para seus filhos que deixaram de ter a alimentação garantida pela escola.

O tema do Dia Mundial da Alimentação da FAO do ano de 2020 foi sobre a importância dos sistemas alimentares sustentáveis, intitulou-se: 'Cultivar, alimentar e preservar'. E o Guia Alimentar para a População Brasileira frisa a necessidade do consumo da 'comida de verdade', da valorização da agricultura familiar, da ingestão dos alimentos orgânicos e agroecológicos (BRASIL, 2014). A própria identidade alimentar, como brasileiros, muitas vezes, representada no prato composto do feijão com arroz, infelizmente fica comprometida em muitos lares onde a renda não é suficiente nem para alcançar esses itens tão essenciais da cesta básica. E ainda, cabe salientar que as orientações da Organização das Nações Unidas para a Alimentação e a Agricultura - FAO,

\footnotetext{
${ }^{6}$ A Lei $\mathrm{n}^{\circ}$ 13.987, de 7 de abril de 2020, que "Altera a Lei ${ }^{\circ} 11.947$, de 16 de junho de 2009, para autorizar, em caráter excepcional, durante o período de suspensão das aulas em razão de situação de emergência ou calamidade pública, a distribuição de gêneros alimentícios adquiridos com recursos do Programa Nacional de Alimentação Escolar (PNAE) aos pais ou responsáveis dos estudantes das escolas públicas de educação básica" (BRASIL, 2020b).

${ }^{7}$ Nesse período foi viabilizado o auxílio emergencial pelo governo federal, para grande parte da população brasileira que encontrava-se sem remuneração, em situação de insegurança alimentar, onde infelizmente a fome voltou a fazer parte dessa realidade, nos primeiros meses da quarentena, foi no valor de seiscentos reais, passando posteriormente a trezentos reais, no entanto, cabe registrar que, essa transferência de renda ficou suspensa desde janeiro de 2021 até momento do fechamento desta publicação, ou seja, março de 2021, embora fosse fundamental a sua manutenção para minimizar os impactos da pandemia da COVID-19 aos mais vulneráveis economicamente.
} 
em época de pandemia, são especialmente para que todos possam fortalecer seu sistema imunológico com uma dieta saudável e consciente, por meio do consumo de 'comida de verdade', que se evite o desperdício de alimentos, para enfrentar à COVID-19 (FAO, 2020).

Segundo o último relatório de Desenvolvimento Humano divulgado, em 2020, o Índice de Desenvolvimento Humano - IDH atual do Brasil caiu 05 posições em relação ao último, encontrase em $84^{\circ}$ na posição mundial, entre 184 países. A pandemia da COVID-19 evidenciou ainda mais as desigualdades, os efeitos devastadores da doença chamam a atenção no mundo todo, bem como os seus reflexos nos sistemas econômicos, sociais e políticos e as ameaças ainda maiores ao desenvolvimento humano, foram registradas mais de 100 milhões de pessoas em pobreza extrema (UNDP, 2020).

\section{IDENTIDADE, CULTURA ALIMENTAR E INTERCULTURALIDADE}

A escolha da alimentação é influenciada por diversos fatores, como o ambiente em que o indivíduo está inserido, os recursos disponíveis, as relações sociais e as experiências individuais. Além desses fatores relacionados à alimentação e ao indivíduo, como higiene, qualidade, preço, sabor, variedade, valor nutricional e aparência, além de determinantes biológicos, socioculturais, antropológicos, econômicos e quantitativos, como descrevem diversos autores, inclusive Jomori et al. (2008).

A comida é um mecanismo de expressão de uma identidade ${ }^{8}$ que também possui uma finalidade social. As práticas alimentares são um aspecto essencial da identidade humana. Os migrantes os levam consigo, junto com suas formas de cozinhar e os utilizam como meio de apoio e integração no novo contexto. Essas práticas atuam como elos entre o passado e o presente, pois é por meio delas que essas duas dimensões se entrelaçam (LUCENA, 2008 citado por FRANZONI, 2016).

A análise fenomenológica faz parte da prática subjetiva em que a consciência individual pode questionar a própria cultura, segundo Gomes (2020). Ainda assim, se tais questões forem socialmente compartilhadas, pode haver uma transformação dos modelos culturais, afinal, a

\footnotetext{
8 Para os efeitos dessa reflexão, vale mencionar que as noções de identidade estão fortemente ligadas ao sentido de lugar e de pertencimento. Nesta análise, cabe mencionar que partimos do entendimento de Silva (2009) que compreende a produção social da identidade e da diferença, abordando que a identidade é um significado - cultural e socialmente atribuído, considerando que a teoria cultural contemporânea registra a ideia de que a identidade e a diferença estão estreitamente associadas a sistemas de representação e, portanto, elas têm que ser representadas.
} 
cultura se reproduz por meio de relações intersubjetivas. Ele cita a sociologia fenomenológica de Schütz como um paradigma apropriado para a análise da cultura, fenômeno dinâmico que se reproduz por meio das interações sociais do mundo da vida cotidiana. Gomes (2020), em sua análise sociológica tenta desvelar o cotidiano concebendo-o como a fonte do sentido que motiva a ação dos atores sociais, ou seja, a rede de sentidos socialmente compartilhados que, normalmente, contribui para legitimar a ordem social.

Franzoni (2016), discute a questão de como a migração tem assumido relevância inegável nos últimos anos e, ultimamente, com a chegada de refugiados de diversos países. Este fato foi um dos principais problemas atuais, pois perante as migrações típicas do trabalho juntam-se migrações em massa de pessoas que deixaram o seu país devido às guerras e, consequentemente, a situações de vida insustentáveis, como vem sendo destacado por diversos autores, inclusive por DIAS et al. (2020) que descrevem sob a ótica do exercício da cidadania como direito humano.

Nowak et al (2020) também enfatiza o valor social dos produtos alimentícios tradicionais, como a polenta em seus contextos culturais, políticos e econômicos mais amplos, destacando os usos e abusos de se tornarem alimentos tradicionais, enfatizando a questão dos projetos de criação de identidade italiana e da literatura acadêmica mais ampla sobre adição e sabor culinários, enfatizando que os chamados alimentos tradicionais devem ser salvos, eles devem ser continuamente reinventados.

A genuína história da culinária e comida italiana é a verdadeira alimentação da cidade e contar sua gênese significa retomar a ancestralidade dos italianos como cidadãos e como o sabor e a criatividade, se completam para criar a culinária favorita do mundo (DICKIE, 2008).

A comida pode ser considerada um elemento cultural, pois as pessoas não comem os mesmos alimentos em todas as culturas. Cada cultura possui um código de conduta alimentar determinado pelos componentes geográficos, ambientais, econômicos, históricos e nutricionais que caracterizam a própria cultura. É prática comum atribuir certos pratos a safras relacionadas e identificar outros com base em seus hábitos alimentares. Quando se chega a outras culturas, diferentes e distantes, principalmente quando a permanência nelas é prolongada, surge o desejo de estar em contato com a própria identidade, de manter abertos os laços com as raízes, hábitos e estes com a própria cultura. A migração envolve uma mudança física nos lugares e nas pessoas com as quais os laços foram estabelecidos, mas também muda de uma cultura para outra. No processo de troca intercultural que pressupõe a migração, passagem incerta em proporção à distância entre a própria cultura e a de adoção, são necessários elementos para manter a identidade. E a alimentação contribui de forma decisiva para a afirmação da identidade do indivíduo e da etnia. A refeição, como ação estruturada e significativa, atua como um elo entre as culturas, promovendo 
a integração. E acredita-se que a mistura cultural gera mudanças culinárias (PRAVETTONI, 2013).

A promoção de sistemas alimentares aumenta a diversidade de culturas e melhora o acesso a alimentos nutritivos, considerando que se constitui em uma grande prioridade política (NEVES e TABAI, 2020). Cabe ressaltar que, para a implementação de políticas, a intersetorialidade passou a ser requisito, visando a sua efetividade por meio das articulações entre os órgãos governamentais e a sociedade civil (TABAI e BEZERRA, 2017).

De acordo com Banini (2017) a identidade territorial deve ser construída por meio de uma ação de pesquisa centrada nas opiniões, atitudes e expectativas das coletividades locais em relação ao território em que vivem ou atuam. As políticas sobre a eficácia e sobre a relação que os vincula à construção de identidades territoriais têm um grande valor superando as fronteiras teóricas do debate científico e tornando-os uma contribuição produtiva para redefinir o desenvolvimento rural político, tentando construir um relacionamento dialético e construtivo com os decisores políticos (BANINI e POLLICE, 2015). A construção de uma identidade territorial também serve para garantir que a comunidade local seja capaz de trocar ideias e opiniões, sugerir soluções, familiarizar-se com as línguas do planejamento territorial e do planejamento econômico (BANINI, 2013).

Na obra intitulada "Comida, memória e afeto: Minas Gerais 300 anos", de acordo com Costa (2021, p.11), a ‘comida de verdade' é aquela constituída além de nutrientes suficientemente capazes de suprir as necessidades nutricionais, sendo que “... cada alimento tem significados simbólico, afetivo, histórico, econômico e social”. Para Maciel (2005), as cozinhas representam o estilo de vida de um povo e o que é colocado para servir uma pessoa, quase sempre simboliza o pertencimento cultural ao local que lhe imprime significados ancestrais, como representado na figura a seguir.

Figura 1 - Mesa posta em uma propriedade de agricultura familiar na serra fluminense.

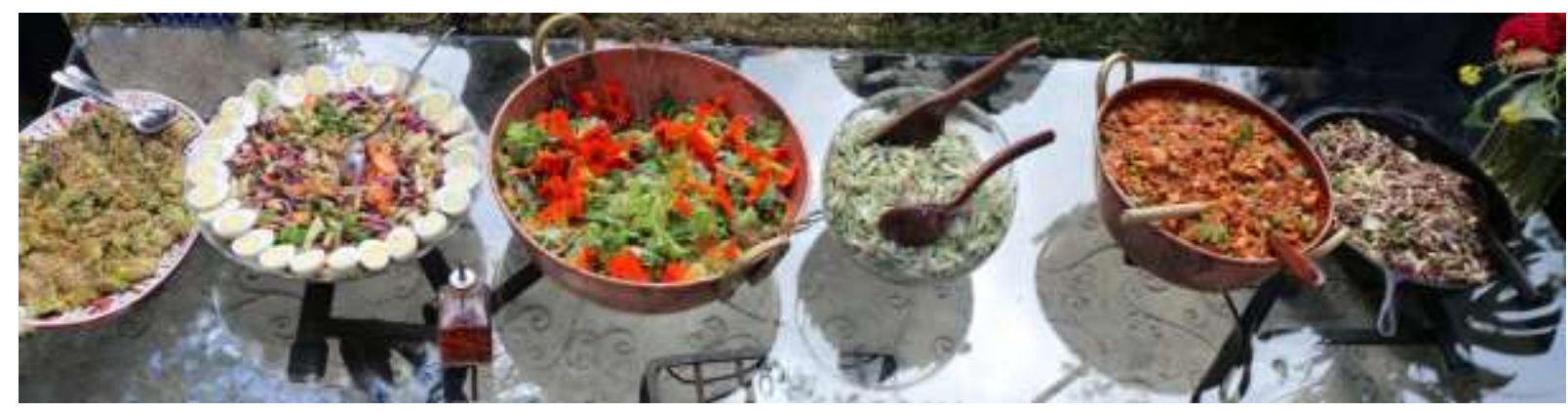

Fonte: Foto dos autores, 2020. 
Mais do que hábitos e comportamentos alimentares, as cozinhas implicam formas de perceber e expressar um determinado modo ou estilo de vida (...). Assim, o que é colocado no prato serve para nutrir o corpo, mas também sinaliza um pertencimento, servindo como um código de reconhecimento social (MACIEL, 2005).

Em estudo realizado na região Sul do Brasil, por exemplo, sobre a percepção dos diversos atores sociais, em relação aos alimentos orgânicos, constatou-se que esses alimentos eram estratégicos para a reprodução social dos agricultores familiares e para a segurança alimentar e nutricional (VOGT e TABAI, 2020).

Neste sentido, o contexto de pandemia nos faz traçar um conjunto de trilhas interdisciplinares que levam aos caminhos da intersetorialidade para alcançar a soberania alimentar, tendo em vista o seu respaldo ético assegurado pela interculturalidade mediante ao diálogo das culturas e será necessário a ocorrência de advertência ética, que vincule a filosofia nova e esta decorre do reconhecimento ético da alteridade. Assim, Sidekum (2003, p.250) aponta o valor da filosofia intercultural, e esta "cria um paradigma interpretativo novo, que opera pela interpretação do próprio e do outro, como resultado da interpelação comum, mútua, em que a voz de cada um é percebida e reconhecida em sua alteridade".

Neste sentido, as linguagens da alteridade fazem presença obrigatória para trazer à tona $\mathrm{o}$ valor do debate necessário sobre a ética intercultural que se manifesta nas suas interrelações e implicações interdisciplinares. E segundo Sidekum (2013), nessa perspectiva em que se desenvolve a experiência da alteridade, a subjetividade será despertada para a vida ética, com uma infinita responsabilidade para com a alteridade.

A vida humana, em seus hábitos culturais, faz sentido ao se ressignificar como condição de cidadania para compreensão do que representa o fenômeno da convivência humana e esta se dá em uma comunidade específica, integrando-se à sociedade como um todo. E tendo em vista o que Sidekum (2003), posiciona como sendo uma ética de desenvolvimento sustentável que leva em consideração a identidade cultural e a unidade na multiplicidade, pois no diálogo das culturas será possível alcançar e concretizar a filosofia intercultural pelas vias do reconhecimento da alteridade.

Ao abranger a eticidade e seus correspondentes indicadores para responder aos temores presentes nos impasses e conflitos que as situações culturais demarcam nas relações territoriais, como consequência será preciso avançar nas políticas públicas intersetoriais. E neste sentido, ao estarem manifestadas as repercussões e ausências destas, em seguida estarão sendo confirmados os alcances interdisciplinares e interculturais para a preservação da vida em pleno impacto da COVID-19, pois ainda se faz urgente repensar o que neste mundo global e excludente ficara sobrestado, no que tange ao valor da plenitude do ser humano, pois: 
Frente aos defensores de um pensar ideológico que enfatiza excludentemente o predomínio do "mundo global", reivindicarmos para as comunidades humanas e sujeitos o projeto de articular tipos de ação no protagonismo e no conflito com vistas para a formação, não só por pequenas partes ou retalhos da humanidade, ou sistemas culturais híbridos, porém reivindicamos "mundos interculturais de vida" em que se possa manifestar, com maior plenitude, "o humano" (ASTRAIN, 2003, p.347).

Numa compreensão positiva de interação da vida, o mundo assiste e vive a pandemia COVID-19 nos noticiários que trazem números assustadores. Como consequências, os diálogos das culturas situam-se como válvulas propulsoras dos cruzamentos culturais para trazer a ciência como marcadora do diálogo multicultural para atingir um protagonismo nos diferentes âmbitos da vida cotidiana. Mas a marcação de territorialidade sendo ampla, ainda se fará recorrente o inédito da vacina para erradicação desta doença que assola a humanidade. E assim, cabe esboçar a necessidade de uma proposta, que fortalecida por uma ética intercultural se possa reconfigurar os atuais impactos e enfrentamentos da atual pandemia. E para sintetizar esta eticidade convém aproximar a reflexão de Sidekum:

A tematização da alteridade quer dizer, antes de tudo, incluir a ética numa nova perspectiva filosófica. A relação com o outro realiza-se na forma da bondade que se chama justiça e responsabilidade infinita para com outro e se concretiza historicamente numa experiência de transcendência, solidariedade e responsabilidade pelo outro. A alteridade é uma experiência de interpelação ética (SIDEKUM, 2013, p. 89).

A eticidade conclamada por Sidekum (2013), na qual sua essência concreta está sendo revelada no contexto cultural em que o impacto à Covid-19 subtrai vidas humanas pelos descasos políticos e econômicos, ditados pelas relações de poder de poucos que concentram rendas e condições, mas espera-se que pesquisas ultrapassem divisas territoriais e possam, de fato, transmitir o valor da vida na dinâmica da ética intercultural.

Os desafios atuais trarão a colaboração entre culturas de forma obrigatória, reconfigurando decisões governamentais, trazendo ações humanitárias imediatas, a exemplo das vacinas. Um exemplo disto poderá se reproduzir 'aliança global por vacina' recém conclamada nas relações internacionais que nosso país está anunciando, perante as pautas das pesquisas mundiais. Assim o diálogo intercultural marcará seu ético papel ao abrir-se para o alcance de todos, indiscriminadamente, sendo a conquista humanitária que todos aspiram num 'piscar de olhos'. No entanto, em diferentes espaços e territórios ainda estamos um pouco longe de alcançarmos a noção ética da interculturalidade, como alerta Sidekum, pois:

Sabemos que a noção ética de interculturalidade está em processo de gestação e que são muitas as perguntas que se abrem a uma Filosofia que assume com franqueza a ação no contexto. Porém já visualizamos que esta contextualização 
exige necessariamente a mediação histórica dos valores em cada cultura concreta (SIDEKUM, 2003, p.346).

É importante destacar ainda que, autores como Maluf (2020b) reafirmam entre outros aspectos, a necessidade do trabalho participativo, intersetorial e sistêmico e o exercício da ciência cidadã e pensamento crítico, para alcançarmos a reconstrução do Estado brasileiro em bases democráticas com respeito a direitos e participação social na formulação e implementação e monitoramentos das políticas públicas inclusive de segurança alimentar, em tempos tão sombrios, como os que estamos vivendo em plena pandemia da COVID-19.

\section{Considerações finais}

O elo ético do 'face a face' com o rosto do outro, vem imprimir o sentido e o valor das linguagens da alteridade como relação de pertencimento e da identidade cultural que se estabelecem em pleno impacto da crise humanitária de valores e de utopias que estão presentes na sociedade hodierna brasileira.

A globalização cultural repercute-se de tal forma como perspectiva que traz valores culturais apresentados de forma meramente utilitária, onde as indústrias culturais ditam as normas aos seus segmentos e 'produtos' culturais, considerando que estes são reproduzidos a exemplo das relações de poder e de seus componentes que, privilegiando o setor de bens e serviços culturais, produzem como consequência uma exclusão. Assim acontecem ações hegemônicas traçadas pelas formas culturais dominantes que são mercantilistas e decorrem de um acirrado consumismo, fruto de concorrências e disputas desiguais e nunca inocentes, inclusive no meio alimentar.

Os marcos da modernidade se dão nos cenários culturais, onde saberes individuais e coletivos vão se integrando numa interrelação permanente da consciência moral, marcadora da identidade e da diferença estabelecendo as mediações que determinam a problemática da identidade cultural e alimentar.

Nos processos identitários estão presentes os protagonismos culturais, a exemplo do impacto da COVID-19 e seus enfrentamentos no atual cenário de crise humanitária. As repercussões da pandemia e suas contradições se reproduzem em meio ao seu enfrentamento para reconhecer a cultura concreta brasileira que, em seu mosaico de diversidades busca estabelecer o valor da plenitude da vida a ser respeitada em suas conquistas interculturais manifestadas pela ciência em seu alcance para todos, independente de condição social.

Neste contexto, convém adotar um pensamento crítico contra esta visão ideológica hegemônica, onde o capital e os meios econômicos ultrapassam e negam o sentido da vida humana, deixando esta para depois e desconsiderando o seu sentido existencial. Mas para reelaborar a 
necessidade de uma ética que contemple a situação de enfrentamento da COVID-19, por exemplo, será urgente um resgate dos saberes culturais acerca do cotidiano que fará ressonância aos diferentes estilos de vida de outras comunidades culturais, num sistema de colaboração mútua, entrecruzando saberes, para assim alcançar a preservação da vida, na sua plenitude.

E como cultura concreta brasileira, segue a presente contextualização dos saberes mediatizados pelos indicativos filosóficos que percorremos nesta trilha da interculturalidade que, decididamente, pelos caminhos da ética pode merecer assumir o protagonismo moral e cultural dos sujeitos numa atuação das linguagens da alteridade como possibilidade para ser alcançada a escuta dos saberes do outro, em respeito a sua história, a sua memória e a sua identidade.

Assim sendo, cabe ser oportunizado o sentido da alteridade como condição de escuta e de responsabilidade para com a palavra que vem do outro, numa infinita relação de reciprocidade, podendo oferecer caminhos para que a cidadania de todos seja assegurada, principalmente na pandemia em que se faz, ainda mais urgente, ser ressignificado o valor da soberania alimentar para a população brasileira.

As práticas do protagonismo moral e cultural dos cidadãos em plenas circunstâncias econômicas em que a sociedade está se refletindo, substancialmente, nas áreas de saúde, educação e meio ambiente, em que os impactos da intersetorialidade estão presentes na distribuição de bens materiais e, também, para assegurar a soberania e segurança alimentar e nutricional, por exemplo. Considerando que tal concretização se faz necessária em decorrência dessa pandemia, que se evidencia em meio a muitas desigualdades sociais cada vez mais acirradas, em especial em países em desenvolvimento como o Brasil.

Além disso, cabe ser repensado o papel das políticas públicas na aplicação neste cenário pandêmico de ausências e de permanentes processos de exclusão social. Como ainda a filosofia intercultural, com seu caráter dialogal e híbrido, para assim inovar dentre as práticas interdisciplinares para oferecer o reconhecimento ético e, também, histórico da alteridade absoluta do outro para ressignificar a compreensão da alteridade como princípio articulador para atingirmos as tão almejadas metas da Agenda 2030, em seus Objetivos de Desenvolvimento Sustentável ODS.

O impacto dessa quarentena para as comunidades mais carentes é ainda mais grave, saber que a fome, que tanto lutamos para não fazer mais parte da nossa realidade brasileira, afinal saímos do Mapa da Fome há pouco tempo, o que já está assombrando, novamente grande parte dos brasileiros.

Acredita-se que publicações como essa sejam mecanismos eficientes para a construção de políticas públicas intersetoriais eficazes, através do maior conhecimento sobre o acesso a dados 
das condições reais de moradia, saúde, alimentação e educação. Afinal, uma das prioridades governamentais deve ser proteger populações mais vulneráveis do ponto de vista econômico e social.

Devido à importância do tema e os poucos estudos sobre como a disseminação desigual da COVID-19 no Brasil tende a potencializar os diferentes impactos de políticas públicas, inclusive ambientais, pois de outra forma as cidades precisarão se reinventar. Considerando essa pandemia vem expor as deficiências das habitações em situações precárias, como falta de saneamento básico, a falta ou o uso inadequado de recursos hídricos, a grande densidade demográfica, ocupações em áreas de risco e, até mesmo, ambientes com ventilação e iluminação inadequadas, pois edificações doentes se tornam fábricas de doenças e degradação humana. Portanto faz-se necessário que novas abordagens sejam contextualizadas para alcançarmos a tão almejada soberania e segurança alimentar para os brasileiros.

\section{Referências}

ASTRAIN, Ricardo. Salas. Ética intercultural e pensamento latinoámericano: problemas e perspectivas de uma ética intercultural no marco da globalização cultural. In: Antônio Sidekum (Org.) Alteridade e multiculturalismo. 1ª . Edição. Ijuí. Editora Unijuí, Rio Grande do Sul. 2003. $464 \mathrm{p}$.

BANINI, Tiziana. Geografie culturali, Milano, Franco Angeli, 2019.

Introduzione. Proporre, interpretare, costruire le identità territoriali. In: Tiziana Banini (Org.), Identità territoriali. Metodi, esperienze, prospettive a confronto, Milano, Franco Angeli, p. 9-27, 2013.

. Proposing a theoretical framework for local territorial identities: concepts, questions and pitfalls, Territorial Identity and Development, v. 2, n. 2, p. 16-23, 2017.

BANINI, Tiziana.; POLLICE, Fábio. Territorial identity as a strategic resource for the development of rural areas. In: Tiziana Banini... [et al] (Org.). Rural development policy and local identities in the European Union Semestrale di Studi e Ricerche di Geografia, 1, p. 7-16, 2015.

BRASIL. Lei $\mathbf{n}^{\mathbf{0}}$ 11.346, de 15 de setembro de 2006. Disponível em: < http://www.planalto.gov.br/ccivil_03/_ato2004-2006/2006/lei/111346.htm> Acesso em 10 junho de 2020.

BRASIL. LEI No 14.016, DE 16 DE JUNHO DE 2020. Dispõe sobre o combate ao desperdício de alimentos e a doação de excedentes de alimentos para o consumo humano. 2020a. Disponível em: https://www.in.gov.br/web/dou/-/lei-n-14.016-de-23-de-junho-de-2020263187111. Acesso em: 02 out 2020.

BRASIL. Ministério da Agricultura, Pecuária e Abastecimento. Orientações para a execução do PNAE durante a situação de emergência decorrente da pandemia do coronavírus (COVID 19). 2020b. Disponível em <https://www.fnde.gov.br/index.php/programas/pnae/pnae-area- 
gestores/pnae-manuais-cartilhas/item/13454-orientaçãos-para-a-execução-do-pnae-pandemia-docoronav\%C3\%ADrus-covid-19> Acesso em 14 out 2020.

BRASIL. Ministério da Saúde. Secretaria de Atenção à Saúde. Departamento de Atenção Básica. Guia alimentar para a população brasileira / Ministério da Saúde, Secretaria de Atenção à Saúde, Departamento de Atenção Básica. - 2. ed. - Brasília: Ministério da Saúde, 2014. CILIOTTA-RUBERY, A. Food Identity and its Impact Upon the Study Abroad Experience. Journal of International Students, v. 6, n. 4, p. 1061-1068, 2016.

COSTA, Cássio. Comida de Verdade. In: SANTOS, Anabele Pires et al. Comida, memória e afeto: Minas Gerais 300 anos. Belo Horizonte: Aliança pela Alimentação Adequada e Saudável. Núcleo, MG. 2021. p. 11-15.

DIAS, Mariana Lobo Menezes; REZENDE, Aline do Carmo; SOUZA, Susan Martin; BENEVENUTO, Monica Aparecida DelRio. Direitos humanos e refúgio no Brasil. Oikos: Família e Sociedade em Debate, v.29, n.2, p. 210-229, 2018.

DICKIE, John. Delizia!: The epic history of the Italians and their food. New York, NY: Free. 2008. 300p.

FOOD AND AGRICULTURAL ORGANIZATION -FAO. FAO oferece 7 dicas de alimentos para enfrentar a crise do COVID19 e respostas sobre seu impacto na alimentação e na agricultura. 2020. Disponível em: http://www.fao.org/brasil/noticias/detail-events/pt/c/1268189 Acesso em: 28 de março de 2020.

FRANZONI, Elisa. A gastronomia como elemento cultural, símbolo de identidade e meio de integração. Dissertação de mestrado em Educação. Faculdade de Ciências Humanas e Sociais. Universidade Nova de Lisboa. 2016. 74p.

FUNDAÇÃO DE AMPARO A PESQUISA DE SÃO PAULO - FAPESP. Covid-19 tem impacto desigual na sociedade. Boletim FAPESP. Junho de 2020.

GOMES, José Vitor Lemes. A sociologia fenomenológica de Alfred Schutz: um paradigma para pensar a cultura In: Helton Rangel Coutinho Junior (Org). Fenomenologia e cultura [recurso eletrônico]: identidades e representações sociais. Ponta Grossa, PR: Atena, p.1-13, 2020.

INSTITUTO BRASILEIRO DE GEOGRAFIA E ESTATÍSTICA - IBGE. Brasil/Rio de Janeiro. 2019. Disponível em: https://cidades.ibge.gov.br/brasil/rj/panorama Acesso em: 18 jun 2020.

.IBGE. 10,3 milhões de pessoas moram em domicílios com insegurança alimentar grave. 2020a. Disponível em https://agenciadenoticias.ibge.gov.br/agencia-noticias/2012agencia-de-noticias/noticias/28903-10-3-milhoes-de-pessoas-moram-em-domicilios-cominseguranca-alimentar-grave Acesso em 07 de outubro de 2020.

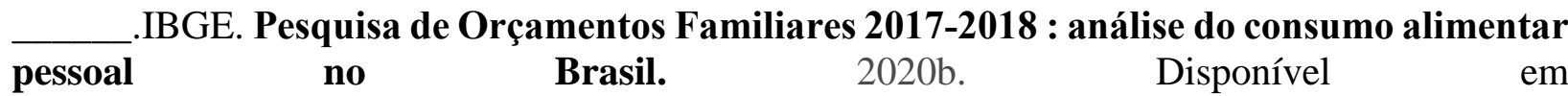
https://biblioteca.ibge.gov.br/visualizacao/livros/liv101742.pdf Acesso em 07 de outubro de 2020.

JOMORI, Manuela Mika; PROENÇA, Rossana Pacheco da Costa; CALVO, Maria Cristina Marino. Determinantes de escolha alimentar. Revista de Nutrição, v. 21, n. 1, p. 63-73, 2008. 
MACIEL, Maria Eunice. Identidade cultural e alimentação. In: Ana Maria Canesqui [et al] (Orgs.). Antropologia e nutrição: um diálogo possível. RJ. Ed. Fiocruz, 2005.

MALUF, Renato Sérgio Jamil. Sobre o Dia Mundial da Alimentação: insegurança alimentar e fome no mundo e no Brasil. 2020a. Disponível em: http://institucional.ufrrj.br/portalcpda/profrenato-maluf-dia-mundial-da-alimentacao-2020/ Acesso em: 19 de out 2020.

Tempos sombrios de pandemia e fome: responsabilidades da pesquisa em soberania e segurança alimentar e nutricional. Segurança Alimentar e Nutricional. Campinas, v.27, p. 1-5, $2020 \mathrm{~b}$.

MORAIS, Luciana Patricia de. Comida, identidade e patrimônio: articulações possíveis. História: Questões \& Debates, Editora UFPR. Curitiba, n. 54, p. 227-254, 2011.

NASCIMENTO, Sueli do. Reflexões sobre a intersetorialidade entre as políticas públicas. Serv. Soc. Soc., 2010. Disponível em: http://www.scielo.br/pdf/sssoc/n101/06.pdf Acesso em 03 mar 2015.

NEVES, Daniele Custódio Gonçalves das ; TABAI, Katia Cilene. Políticas públicas intersetoriais de segurança alimentar e nutricional no Brasil. In: Lúcia Aparecida Valadares Sartório... [et al.] (Org.). Políticas públicas e práticas sociais: cidadania, saúde, educação, comunicação e segurança alimentar. São Paulo: Editora Livraria da Física, p. 49-68, 2020.

NOWAK, Zachary; JONES, Bradley M.; ASCIONE, Elisa. Disciplining Polenta: a parody on the politics of saving food. Gastronomica. v.20, n.2, p. 1-11, 2020. Disponível em: https://online.ucpress.edu/gastronomica/article-abstract/20/2/1/110252 Acesso em: 22 Outubro 2020.

ORGANIZAÇÃO DAS NAÇÕES UNIDAS - ONU. 17 Objetivos Para Transformar o Mundo. 2015. Disponível em: https://nacoesunidas.org/pos2015/agenda2030/ Acesso em: 21 jun 2019.

PRAVETTONI, Di Riccardo. Il Cibo come elemtno di identità culturale nel processo migratorio, 2013.

SIDEKUM, Antônio. Educação e Interpelação Ética. Revista da FAEEBA. Educação e contemporaneidade. v. 22, n. 39, p. 85-94, 2013.

SILVA, J.G. Agora, defender-se do vírus...E depois? Segurança Alimentar e Nutricional. Campinas, v.27, p. 1-4, 2020.

SILVA, José Graziano da. Agora, defender-se do vírus...E depois? Segurança Alimentar e Nutricional. Campinas, v.27, p. 1-4, 2020.

SILVA, Tomaz Tadeu da. A produção social da identidade e da diferença. In: Tomaz Tadeu da Silva (Org). Stuart Hall, Kathryn Woodward. Identidade e diferença: a perspectiva dos estudos culturais. 9.ed. Petrópolis, RJ: Vozes, 2009.

TABAI, Katia Cilene; BEZERRA, Isabelle Germano Coelho. The intersetoriality between the Food Acquisition Program and the National School Food Program in a Brazilian Municipality: Advances, Obstacles and Possibilities. In: International Conference on Childhood Obesity Conference Book, Lisboa, Portugal, 2017. p. 87. 
TABAI, Katia Cilene. Políticas de segurança alimentar e saúde pública. In: Lucia Aparecida Valadares Sartório (Org.). Sustentabilidade: qualidade de vida, economia solidária e educação. 1ed. Nova Iguaçu: Editora Entorno, 2018, v.1, p. 137-156.

. Segurança alimentar e nutricional no contexto da intersetorialidade In: Inocuidade dos Alimentos. 1 ed.São Paulo: Atheneu, 2017, v.1, p. 19-30.

UNITED NATIONS CHILDREN'S FUND - UNICEF. Impactos primários e secundários da Covid-19 em Crianças e Adolescentes. Disponível em: https://www.unicef.org/brazil/media/9966/file/impactos-covid-criancas-adolescentes-ibopeunicef-2020.pdf Acesso em 22 de ago de 2020.

UNITED NATIONS DEVELOPMENT PROGRAMME (UNDP). Human Development Report 2020. The next frontier: Human development ant the anthropocene. Disponível em: hdr2020.pdf (undp.org) Acesso em: 15 de dezembro 2020.

VOGT, Flávio; TABAI, Katia Cilene. Alimentos orgânicos na percepção de diferentes atores sociais do município de Frederico Westphalen-RS. In: Lúcia Aparecida Valadares Sartório (Org)...[et al.]. Políticas públicas e práticas sociais: cidadania, comunicação, segurança alimentar, saúde e educação. São Paulo: Editora Livraria da Física, 2020.

Recebido em: 26/11/2020 Aprovado em 20/01/2021 